\title{
Sulodexide in the Treatment of Patients with Early Stages of COVID-19: A Randomized Controlled Trial
}

\author{
Alejandro J. Gonzalez-Ochoa1,20 Joseph D. Raffetto ${ }^{3}$ Ana G. Hernández ${ }^{4}$ Nestor Zavala 5 \\ Obed Gutiérrez $^{6,7}$ Arturo Vargas ${ }^{8}$ Jorge Loustaunau ${ }^{9}$
}

${ }^{1}$ Department of Vascular-Endovascular Surgery, CLINEDEM, Colonia Comercial, San Luis Rio Colorado, Sonora, México

2 Division of Vascular Surgery, Department of Surgery, Hospital General de Zona No12 Instituto Mexicano Seguro Social, San Luis Rio Colorado, Sonora, México

${ }^{3}$ Department of Surgery, Brigham and Women's Hospital, VA Boston Healthcare System, Harvard University, Boston, Massachusetts, United States

${ }^{4}$ Department of Otorhinolaryngology, CLINEDEM, Colonia Comercial, San Luis Rio Colorado, Sonora, México

${ }^{5}$ Hospital General de Zona No12 Instituto Mexicano Seguro Social, San Luis Rio Colorado, Sonora, México

${ }^{6}$ Department of Emergency Medicine, Hospital General de Zona No12 Instituto Mexicano Seguro Social, San Luis Rio Colorado, Sonora, México

${ }^{7}$ Department of Emergency, Hospital General, San Luis Rio Colorado, Sonora, México

8 Urban Outpatient Care Center, Secretaria de Salud, San Luis Rio Colorado, Sonora, México

${ }^{9}$ Department of Emergency, Hospital General de Zona No12 Instituto Mexicano Seguro Social, San Luis Rio Colorado, Sonora, México
Address for correspondence Alejandro J. Gonzalez-Ochoa, MD, Department of Vascular-Endovascular Surgery, CLINEDEM, callejón 5 de mayo y calle 7 No 791, Colonia Comercial, 83449, San Luis Rio Colorado, Sonora, México (e-mail: alex8as2@yahoo.com.mx).
Abstract
Keywords
- COVID-19
- sulodexide
- D-dimer
- early treatment
- SARS-CoV-2
- C-reactive protein

Severe acute respiratory syndrome coronavirus 2 (SARS-CoV-2) may induce several vascular endothelial-dependent systemic complications, and sulodexide has pleiotropic actions on the vascular endothelium, which may prove beneficial. We aimed to assess the effect of sulodexide when used within 3 days of coronavirus disease 2019 (COVID-19) clinical onset. We conducted a randomized placebo-controlled outpatient trial. To be included, patients must have been at high risk for severe clinical progression. Participants received sulodexide (oral 1,000 LRU/d) or placebo for 21 days. The primary endpoint was the need for hospital care. Also assessed were patients' need for supplemental oxygen as well as D-dimer and C-reactive protein (CRP) levels, thromboembolic events, major bleeding, and mortality. A total of 243 patients were included in the per-protocol analysis from June 5 to August 30, 2020. Of these, 124 received sulodexide and 119 received a placebo. Only $17.7 \%$ of the patients in the sulodexide group required hospitalization, compared with $29.4 \%$ in the placebo group $(p=0.03)$. This benefit persisted in the intention-to-treat analysis (15\% in sulodexide group vs. $24 \%$ with placebo $[p=0.04])$. With sulodexide, fewer patients required supplemental received

December 26, 2020

accepted after revision

March 5, 2021

published online

March 7, 2021 (c) 2021. Thieme. All rights reserved. Georg Thieme Verlag KG,

Rüdigerstraße 14,

70469 Stuttgart, Germany
DOI https://doi.org/ 10.1055/a-1414-5216. ISSN 0340-6245. 
oxygen (30 vs. $42 \%[p=0.05]$ ). After 2 weeks, fewer patients had D-dimer levels $>500 \mathrm{ng} / \mathrm{dL}$ (22 vs. $47 \%[p<0.01])$, and patients also had lower mean CRP levels (12.5 vs. $17.8 \mathrm{mg} / \mathrm{dL}[p<0.01])$. There were no between-group differences in thromboembolic events, major bleeding, or mortality. Treatment of COVID-19 patients with sulodexide, when provided within 3 days of clinical onset, improved their clinical outcomes. Although the results should be confirmed, sulodexide could be valuable in an outpatient setting.

\section{Introduction}

The novel coronavirus disease 2019 (COVID-19) has developed into a pandemic ${ }^{1}$ that has changed our way of life to a degree that has yet to be determined. The reported percentage of infected patients who require hospital care is between 15 and 25\%. ${ }^{2,3}$ However, the virus' high contagiousness has resulted in health care systems worldwide being placed under massive strain due to the vast numbers of patients requiring hospital care. Effective early treatment to prevent the more severe effects of COVID-19 could improve this situation.

The endothelial surface layer in the lungs plays a critical role in the immune response to SARS-CoV-2 infection, both as an effector and as a target organ. There is evidence of viral inclusion $^{4}$ in the endothelium and diffuse inflammation (endothelialitis), which trigger a systemic release of inflammatory cytokines. ${ }^{5}$ Such conditions diminish the endothelium's protective properties. The resulting proinflammatory and prothrombotic state can cause microvascular thrombosis, ${ }^{6,7}$ which might explain the impaired systemic function of various vascular beds and their clinical sequelae in some patients. ${ }^{8-10}$ COVID-19-induced endothelialitis may be a particularly relevant concern for vulnerable patients with pre-existing endothelial dysfunction, which is associated with males, old age, and chronic comorbidities-all of which are linked with adverse disease outcomes. ${ }^{11,12}$

Sulodexide is a compound of two glycosaminoglycans (GAGs): a fast-moving heparin fraction (80\%) and dermatan sulfate (20\%). Although possibly better known for its antithrombotic effect, ${ }^{13}$ sulodexide's endothelial-protective properties may contribute a benefit of equal or greater importance in the early stages of COVID-19. ${ }^{14,15}$ As a precursor for the synthesis of GAGs, sulodexide can help restore a shredded endothelial glycocalyx and prevent further degradation. ${ }^{16,17}$ This improvement restores endothelial barrier function and allows the endothelium to better modulate the generation of key inflammatory molecules, while at the same time downregulating its response to them. ${ }^{17,18}$ This can help prevent the aberrant immunothrombosis reaction seen in some patients. Sulodexide's antithrombotic and profibrinolytic effects may still be significant against the procoagulant state caused by SARS-CoV-2. Finally, sulodexide is also associated with a lower bleeding risk than is seen with other oral anticoagulants. $^{19}$
Reports suggest low-molecular-weight heparin (LMWH) is accompanied by a reduction in mortality when used in a hospital setting. ${ }^{20}$ It has been hypothesized on this basis that patients on chronic anticoagulation may experience lower incidences of thromboembolic events upon hospitalization for COVID-19; thus, research into its outpatient use in ameliorating the disease's clinical course has been proposed. $^{21,22}$ Few outpatient trials for nonanticoagulation and nonvaccine-related studies are ongoing. ${ }^{23}$ However, prospective randomized trials on COVID-19 patients are pending and largely overlook the potential of pulmonary endothelial cells as a therapeutic target. ${ }^{24,25}$

With this premise, we decided to evaluate whether sulodexide's pleiotropic properties prevent the SARS-CoV-2mediated endothelialitis with hypercoagulability and inflammation. This benefit, if found, could improve clinical outcomes and translate into a reduced need for hospital care.

\section{Methods}

\section{Study Design}

We performed a prospective, randomized placebo-controlled trial with a parallel-group design to assess the effect of sulodexide on clinical outcome in consecutive patients suffering from the early clinical stages of COVID-19, as defined in - Table 1.

The recruiting period ran from June 5 to August 5, 2020, with the follow-up period concluding on August 30, 2020. The study site is located in San Luis Rio Colorado, Sonora, a border port of entry in Mexico's northwestern region. As of August 5, 2020, 28,990 confirmed COVID-19 cases had been reported within a 100 -mile radius of this site, including cities in the United States. We conducted this trial in compliance with the Declaration of Helsinki. The trial was boardreviewed by the Universidad Autonoma de Baja California Faculty of Medicine Campus Mexicali at the Department of Ethics and Investigation Committee and has the approval number FMM/CEI/0011/2020-2. Although some participants were U.S. residents, all were under the supervision of physicians and hospitals in Mexico.

\section{Patients}

We anticipated difficulties in recruiting eligible patients and consequently utilized social media outreach, as well as contacting primary care physicians in state and private clinics for early referral. We reached out to health care 
Table 1 Inclusion, exclusion, and elimination criteria

\begin{tabular}{|c|c|c|}
\hline Inclusion criteria & Exclusion criteria & Elimination criteria \\
\hline $\begin{array}{l}\text { - Age }>40 \text { years } \\
\text { - Male or female } \\
\text { - Body mass index of } 18-35 \mathrm{~kg} / \mathrm{m}^{2} \\
\text { - The onset of } 3 \text { days or less of } \\
\text { suspected COVID-19 symptoms } \\
\text { defined as any two of cough, } \\
\text { fever, or headache. Plus one of } \\
\text { sniff, dyspnea, diarrhea, loss of } \\
\text { smell/taste, conjunctivitis, or } \\
\text { body/muscle ache. } \\
\text { - Sign informed consent } \\
\text { - High level risk to develop a severe } \\
\text { clinical progression of COVID-19a }\end{array}$ & $\begin{array}{l}\text { - A negative RT-PCR SARS-CoV- } 2 \text { test result } \\
\text { - Known pregnancy } \\
\text { - Prolonged anticoagulation in the last } 6 \text { months }{ }^{\mathrm{b}} \\
\text { - History of deep vein thrombosis in the } \\
\text { - Srevious } 6 \text { months } \\
\text { - Severe clinical symptoms that warrant } \\
\text { immediate hospital care } \\
\text { - Chronic use of steroid medication in } \\
\text { the previous } 6 \text { months } \\
\text { - Bed confinement in the last } 6 \text { months } \\
\text { - Already hospitalized for other reasons. } \\
\text { - Previous treatment for COVID-19 }\end{array}$ & $\begin{array}{l}\text { - Withdrawal of informed consent } \\
\text { - Lost to follow-up } \\
\text { - A negative RT-PCR SARS-CoV-2 } \\
\text { test result not available }\end{array}$ \\
\hline
\end{tabular}

Abbreviations: BMI, body mass index; RT-PCR, reverse-transcriptase polymerase chain reaction.

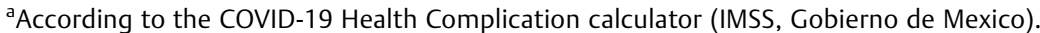

${ }^{\text {b }}$ Start of anticoagulation after trial inclusion was not a criterion for exclusion.

workers at hospitals admitting COVID-19 patients and household members known to be hosting COVID-19-positive patients, as they were at high risk of infection and had firsthand knowledge of the symptoms.

Virtual communication was used for patient-eligibility screening, and the inclusion and exclusion criteria are summarized in - Table 1. Key inclusion criteria were the combination of symptoms described above and being deemed at high risk $(>50 \%)$ of severe clinical disease progression. Risk was assessed according to the percentage risk calculated using the COVID-19 Health Complication (C19HC) calculator (IMSS, Gobierno de Mexico), which considers the importance of various chronic comorbidities (-Supplementary Table S1 [available in the online version]). ${ }^{26}$ Important exclusion criteria included a negative reverse-transcriptase polymerase chain reaction (RT-PCR) SARS-CoV-2 test result and prolonged anticoagulation treatment. Once the trial was ongoing, the initiation of anticoagulant medication at a prophylactic dose was not considered a criterion for elimination. However, due to the possible risk of bleeding complications, these patients underwent stricter follow-ups. Eligible patients signed informed consent forms and were scheduled the earliest for blood tests and RT-PCR SARS-CoV2 test.

\section{Study Protocol}

Group allocation was performed at the research site through sequential randomization using computer software provided by Castor Electronic Data Capture (EDC; Amsterdam, the Netherlands). The software generated a permuted block randomization sequence in a 1:1 ratio with no underlying strata. The medical team in charge of the patients and treatment regimens was blinded to group allocation.

The indicated treatment dose was 500 LRU (lipase releasing units) twice daily for 3 weeks. On a 7-day schedule, the research site distributed 250 LRU masked capsules of sulodexide (Vessel due F, Alfasigma, Mexico) or masked capsules of placebo. A patient representative would collect the medication at the study site. When this was not possible, a staff member was responsible for its delivery at the patient's home. Although 250 RLU twice daily has been observed to produce effective plasma concentrations in vitro and is regularly prescribed in daily practice, ${ }^{27}$ we chose the higher 500 RLU dosing regimen based on the SURVET (Sulodexide in Secondary Prevention of Recurrent Deep Vein Thrombosis) study, in which an antithrombotic effect was safely achieved in a clinical setting. ${ }^{28}$ Placebo capsules were prescribed to the control group according to the same regimen. Due to local logistical limitations resulting from the regional pandemic lockdown, which jeopardized the medication's timely distribution, the lead researcher was not blind to group allocation. Apart from being used to provide the study medication and perform follow-ups on study endpoints, the research site was not involved in the disease's primary treatment. Patients were encouraged to continue with the standard care recommended by their health care providers. ${ }^{29}$ Some of the researchers were involved in the complementary treatment of patients outside the research site; however, they were blind to group allocation.

Independent authorized laboratories processed the RTPCR SARS-CoV-2 tests. Since the test result was not reported for several days, participants continued with the follow-up as scheduled. If confirmed positive, the participant continued in the trial. If negative, the medication treatment was suspended and the patient was excluded from the data analysis.

We performed follow-ups to assess the study endpoints via remote communication with participants or household members every 7 days or as deemed necessary during the 3week participation period. If no virtual form of contact was possible, we scheduled a field visit to the participant's home. New blood tests were scheduled on follow-up day 14 for secondary endpoint assessments. Laboratory staff followed strict safety protocols. If we were unable to contact the participant during the follow-up period and no data were available other than the initial inclusion survey, the patient was excluded from the final analysis once mortality was ruled out as the cause of inability to follow up. 
If the patient's symptoms worsened, we recommended the patient undergo an emergency department examination with their health care provider. A visit to the hospital's emergency department was not considered a study endpoint unless it resulted in formal admission to the COVID-19 hospital ward. The in-house protocols for clinical management and admission applied by hospitals included-but were not limited to-respiratory failure (oxygen saturation $<90 \%$, severe hypoxemia [partial pressure of oxygen $<60 \mathrm{~mm} \mathrm{Hg}$ ] or breathing rate $>30$ breaths per minute while breathing ambient air); abnormal chest X-ray compatible with COVID19-associated pneumonia; and relevant clinical changes together with clinically significant laboratory abnormalities. ${ }^{30}$ The hospital's admission decision (or, alternatively, the determination of a need for at-home supplemental oxygen) was left to discretion of the emergency department physician, who was blind to group allocation. If the patient required hospital care, we suspended the oral dose of sulodexide or placebo but continued gathering data on the patient's progression and included that data in the final analysis. The research team was not involved in any of the treatment decisions made during hospital care, but in such cases the follow-up was extended beyond the specified 3week period until we could define an outcome or until the trial ended. Sulodexide was not resumed after discharge from the hospital.

\section{Data Sources}

Data were collected using Castor EDC software for validation and monitoring and kept a hard copy on file at the research site.

The data collected from each patient included the following: (1) the patient's general demographics; (2) clinical characteristics and outcomes; (3) serum and RT-PCR SARSCoV-2 test results; and (4) the duration and dosages of all treatments the participant received, adverse events, and medication adherence.

\section{Study Endpoints}

Outcomes were assessed at day 21 after randomization. The primary endpoint was the need for hospital admission for clinical care. Secondary clinical endpoints were the total length of stay (LOS) in the hospital due to COVID-19; the need for and duration of supplemental oxygen at home, in the hospital, or both; the need for mechanical ventilation; the occurrence of a thromboembolic event or major bleeding (define as fatal bleeding or bleeding causing a fall in hemoglobin levels of $20 \mathrm{~g} \mathrm{~L}^{-1}$ or more, or leading to transfusion of 2 or more units of whole blood or red blood cells); and mortality. Serum levels of D-dimer (using a chemiluminescence assay with the reference range of $0-500 \mathrm{ng} \mathrm{FEU} / \mathrm{mL}$ ), Creactive protein (CRP; using a turbidimetric assay with the reference range of $0-6 \mathrm{mg} / \mathrm{L})$, and creatinine $(\mathrm{Cr})$ were measured as secondary laboratory endpoints.

\section{Statistical Analysis}

The need for hospital care was the endpoint used to determine the sample size required for statistical significance.
Since the patients included were at high risk of severe COVID19 clinical progression, we estimated that $40 \%$ of the patients would require hospital care. Since there is no precedent for treating COVID-19 patients with sulodexide, we assumed that sulodexide treatment could result in a $25 \%$ reduction in hospital admissions based on results from other clinical trials that outlined benefits similar to the one expected with this trial. ${ }^{31}$ We calculated a required sample size of 100 patients in each group based on a $t$-test difference between two independent means with an effect size of 0.4 , an $\alpha$ error of 0.05 , and a power of $80 \%$. The sample size increased to 120 participants per group when factoring in an estimated 20\% rate of attrition.

Relative risk (RR) estimates are shown with a 95\% confidence interval $(\mathrm{CI})$ and calculated using the MedCalc software (MedCalc Software Ltd., Olsted, Belgium). All pvalues are two-sided and shown without adjustment for multiple testing. The study team has retained the complete database.

Quantitative variables are expressed as means ( \pm standard deviation) and qualitative variables are expressed as frequencies and percentages. Differences in means were calculated using the Student's $t$-test, while differences in percentages were assessed using the $\mathrm{X}^{2}$-test. Before and after serum levels in the same patients were analyzed using two paired $t$-tests. If the data were not normally distributed, a Wilcoxon test was used. A Kaplan-Meier curve was used to graphically compare time to endpoint for hospital admission and mortality.

Although an intention-to-treat analysis was planned initially, the inclusion of clinically suspected COVID-19 patients and the exclusion of patients who began the treatment before reporting a negative RT-PCR SARS-CoV2 test result led to a per-protocol data analysis instead. However, an additional intention-to-treat analysis was performed for the primary and secondary endpoints of importance. Data analysis was performed using SPSS software (IBM SPSS Statistics for Windows, version 26, IBM Corp., Armonk, New York, United States). Data were missing for less than $10 \%$ of patients; this was compensated for by multiple imputation analysis. However, no primary endpoint result data were imputed. When missing, the last known value was used for analysis. An independent data monitoring committee had access to the accumulating data in general, with safety monitoring as the major purpose.

\section{Results}

Of the 656 suspected COVID-19 patients assessed for eligibility, a total of 312 underwent randomization for group allocation. Thirty-one of the 312 patients reported a negative RT-PCR SARS-CoV-2 test result (14 out of 157 [8.9\%] in the sulodexide group and 17 out of 155 [10.9\%] in the control group). A total of 38 patients were lost to follow-up (19 out of 157 [12.1\%] in the sulodexide group and 19 out of 155 [12.2\%] in the control group). A total of 243 patients (124 patients in the sulodexide group and 119 in the placebo group) were 


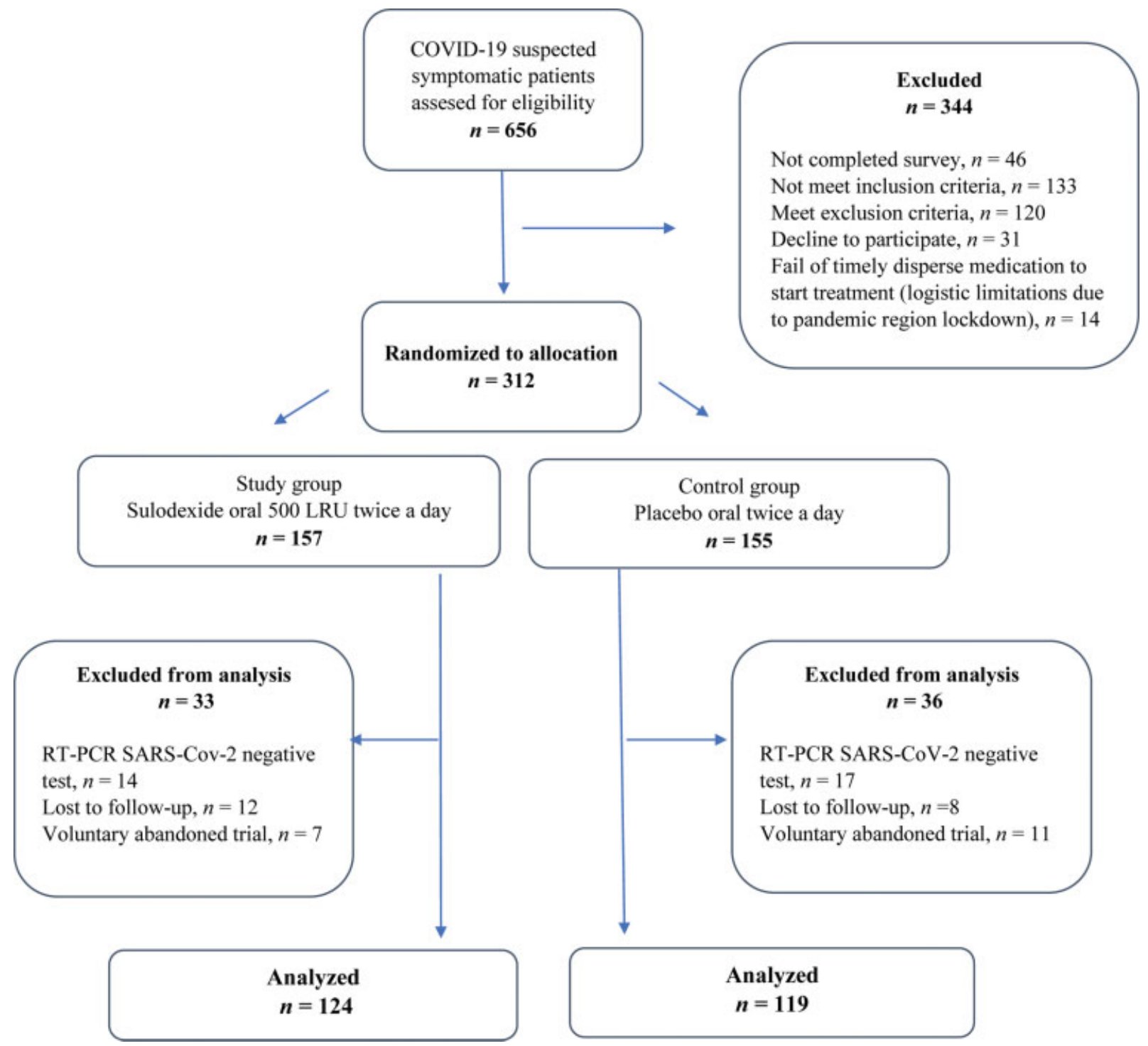

Fig. 1 CONSORT flow diagram.

eligible for final data analysis (-Fig. 1). Demographics and clinical characteristics were similar in both groups (see - Table 2).

\section{Primary Endpoint}

Overall, 57 of the 243 patients (23.4\%) required hospital care during the 21-day follow-up (22 of 124 [17.7\%] in the sulodexide group and 35 of 119 [29.4\%] in the placebo group, with a RR of $0.6,95 \% \mathrm{CI}$ of $0.37-0.96 ; p=0.031$ ). The estimated number of patients who needed to be treated with sulodexide rather than standard care for one additional patient to benefit was 8.5. When including the 312 randomized patients in the intention-to-treat analysis (-Supplementary Table $\mathbf{S 2}$ [available in the online version]), 23 of 155 patients (14\%) in the sulodexide group required hospital care versus 38 of 157 (24\%) in the placebo group (RR of $0.6 ; 95 \%$ CI of $0.38-0.97$; $p=0.037)$. - Fig. 2 shows the Kaplan-Meier curve for time to hospital admission (log rank: $p=0.05$; Breslow: $p=0.04)$.

\section{Secondary Clinical Endpoints}

Secondary endpoint results are summarized in -Table 2. Most importantly, 87 of the 243 patients (35.8\%) developed respiratory symptoms requiring supplemental oxygen (37 out of 124 [29.8\%] in the sulodexide group vs. 50 out of 119 [42\%] in the control group [RR of $0.71 ; 95 \%$ CI of $0.5-1$; $p=0.053)$. These results were slightly modified in the intention-to-treat analysis (39 out of 155 in the sulodexide group vs. 56 out of 157 in the placebo group [RR of $0.71 ; 95 \% \mathrm{CI}$ of $0.5-0.9 ; p=0.046])$. Patients in the sulodexide group required supplemental oxygen for fewer days than did those in the placebo group $(p=0.02)$. There was no difference between groups regarding mean hospital LOS $(p=0.21)$ or mortality rate ( 3 out of 124 [2\%] vs. 7 out of 119 [6\%] with a RR of $0.41 ; 95 \%$ CI of $0.10-1.55 ; p=0.19)$. - Fig. 2 shows the Kaplan-Meier mortality curve (log rank: $p=0.16$ ).

\section{Secondary Laboratory Endpoints}

There was no between-group difference in serum levels of either D-dimer or CRP at baseline. Mean D-dimer levels at 
Table 2 General demographics, comorbidities, and outcome

\begin{tabular}{|c|c|c|c|c|}
\hline & Sulodexide $(n=124)$ & Placebo $(n=119)$ & RR (95\% CI) & $p$-Value \\
\hline \multicolumn{5}{|l|}{ Demographics } \\
\hline Age in years, mean (SD) & $55.3(10.3)$ & $54(10.9)$ & - & 0.26 \\
\hline Female, $n(\%)$ & $64(52)$ & $64(54)$ & $0.95(0.75-1.21)$ & 0.73 \\
\hline BMI, mean (SD) & $29(4.0)$ & $28.7(3.2)$ & - & 0.30 \\
\hline \multicolumn{5}{|l|}{ Chronic comorbidities, $n$ (\%) } \\
\hline Diabetes mellitus & $22(18)$ & $28(24)$ & $0.75(0.45-1.24)$ & 0.26 \\
\hline Hypertension & $48(39)$ & $35(29)$ & $1.31(0.92-1.87)$ & 0.13 \\
\hline COPD & $30(24)$ & $26(22)$ & $1.10(0.69-1.75)$ & 0.66 \\
\hline Cardiovascular disease & $28(23)$ & $23(19)$ & $1.16(0.71-1.90)$ & 0.53 \\
\hline $\mathrm{C} 19 \mathrm{HC}$ risk calculator, mean (SD) ${ }^{\mathrm{a}}$ & $68(14)$ & $66(14)$ & - & 0.32 \\
\hline \multicolumn{5}{|l|}{ Outcome } \\
\hline Need for hospital care, $n(\%)$ & $22(18)$ & $35(29)$ & $0.60(0.37-0.96)$ & 0.03 \\
\hline Length of hospital care (days), mean (SD) & $6.3(4.1)$ & $7.8(4.5)$ & - & 0.21 \\
\hline Need for supplemental oxygen, $n(\%)^{\mathrm{b}}$ & $37(30)$ & $50(42)$ & $0.71(0.50-1.00)$ & 0.05 \\
\hline LOD of supplemental oxygen, mean $(\mathrm{SD})^{\mathrm{b}}$ & $9(7.2)$ & $11.5(9.6)$ & - & 0.02 \\
\hline Mortality, $n(\%)$ & $3(2)$ & $7(6)$ & $0.41(0.10-1.55)$ & 0.19 \\
\hline Invasive mechanical ventilation, $n(\%)$ & $3(2)$ & $6(5)$ & $0.47(0.12-1.87)$ & 0.29 \\
\hline Hemodialysis, $n(\%)$ & 0 & 0 & - & - \\
\hline Thromboembolic events, $n(\%)$ & $2(2)$ & $2(2)$ & $0.95(0.13-6.70)$ & 0.96 \\
\hline \multicolumn{5}{|l|}{ Laboratory findings } \\
\hline \multicolumn{5}{|l|}{ D-dimer baseline, $\mathrm{ng} / \mathrm{dL}$} \\
\hline Mean (SD) & $294(117)$ & $318(131)$ & - & 0.12 \\
\hline$>500, n(\%)$ & $14(11)$ & $21(18)$ & $0.63(0.34-1.19)$ & 0.16 \\
\hline \multicolumn{5}{|l|}{ D-dimer at week 2} \\
\hline Mean (SD) & $465(630)$ & $898(1215)$ & - & $<0.01$ \\
\hline$>500, n(\%)$ & $27(22)$ & $56(47)$ & $0.46(0.31-0.67)$ & $<0.01$ \\
\hline \multicolumn{5}{|l|}{ CRP, mg/dL } \\
\hline Baseline, mean (SD) & $10.6(6.4)$ & $10.1(6.9)$ & - & 0.55 \\
\hline Week 2, mean (SD) & $12.5(10.2)$ & $17.8(11.5)$ & - & $<0.01$ \\
\hline \multicolumn{5}{|l|}{ Creatinine at week $2, \mathrm{mg} / \mathrm{dL}$} \\
\hline$>1.6$ & $11(8.8)$ & $12(10.0)$ & $0.87(0.40-1.91)$ & 0.74 \\
\hline
\end{tabular}

Abbreviations: BMI, body mass index; Cl, confidence interval; COPD, chronic obstructive pulmonary disease; CRP, C-reactive protein; LOD, length of days; $n$, number of patients; RR, relative risk; SD, standard deviation.

a Percentage is given by the COVID-19 Health Complication (C19HC) risk calculator (Gobierno de Mexico, IMSS).

bIncluding the total number of days patients needed supplemental oxygen at home or in hospital. Some patients continued supplemental oxygen at home after hospital care or started supplemental oxygen at home and later required hospital care.

week 2 were significantly higher in the placebo group than in the sulodexide group $(p<0.01)$. A total of 27 of the 124 patients (22\%) in the sulodexide group showed a D-dimer value $>500 \mathrm{ng} / \mathrm{dL}$, compared with 56 out of $119(47.05 \%)$ in the placebo group (RR of $0.46 ; 95 \% \mathrm{CI}$ of $0.31-0.67 ; p>0.01$ ). Mean CRP levels at week 2 were lower in the sulodexide group than in the placebo group $(p<0.01)$.

\section{Adherence and Safety}

Medication adherence was assessed at each follow-up examination and was also verified indirectly by counting the number of capsules left in the medication blisters. The results are summarized in - Table 3. A total of 17 of the 243 patients (13.7\%) felt they had clinically recovered, resulting in voluntary premature interruption of medication. This interruption occurred after a minimum of 14 days of treatment in all such patients, none of whom later required hospital care or supplemental oxygen. None of the patients who suspended medication were excluded from the final analysis.

An adverse event was severe enough to cause medication cessation in 14 of the 243 patients (5.7\%), with no betweengroup difference. Gastrointestinal discomfort was the main 


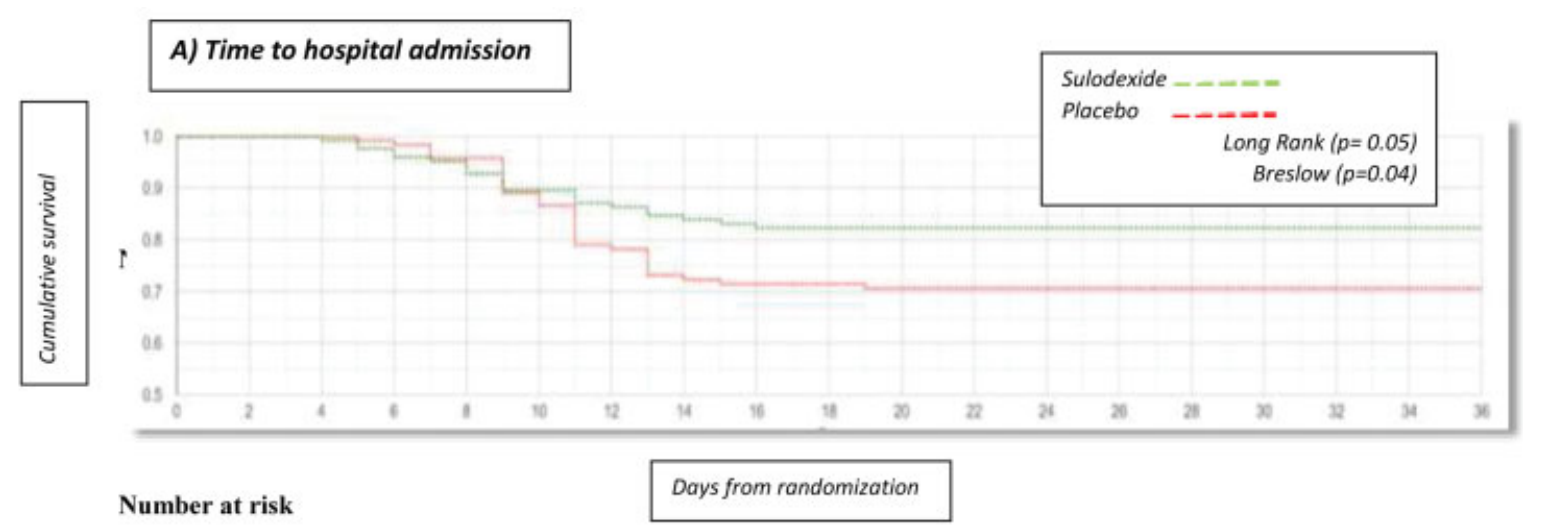

\begin{tabular}{|l|c|c|c|c|c|c|}
\hline Sulodexide & 124 & 123 & 112 & 104 & 102 & 102 \\
\hline Placebo & 119 & 119 & 109 & 83 & 84 & 84 \\
\hline Day & 0 & 5 & 10 & 15 & 20 & 26 \\
\hline
\end{tabular}

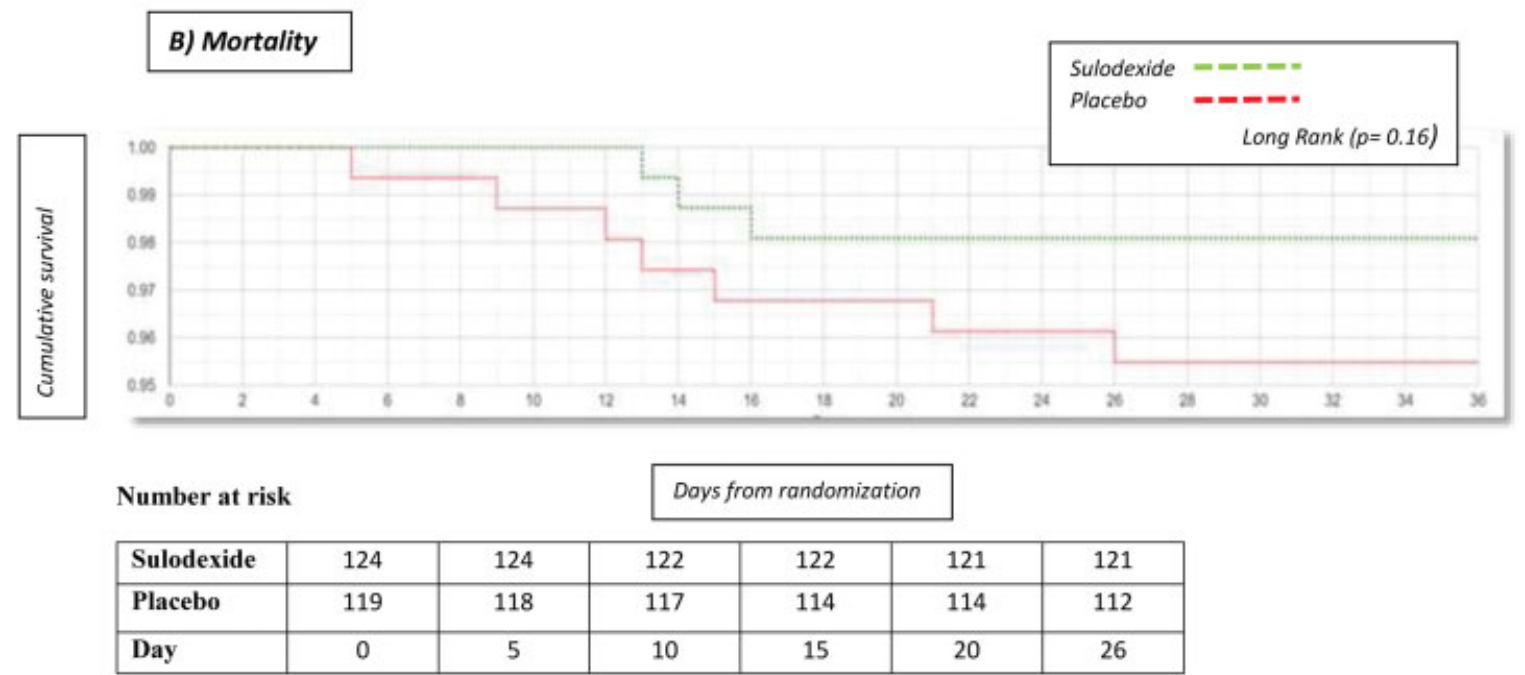

Fig. 2 Time to even for hospital admission and mortality in patients with COVID-19. Shown is an expanded axis of the cumulative incidence of events in both groups; from randomization until the end of the 21-day follow-up (with prolonged follow-up until the defined endpoint or the end of the trial period). In panel (A), the use of sulodexide shows a statistically significant difference benefit for time to hospital admission (log rank $[p=0.05]$ and Breslow $[p=0.04])$. Panel (B) displays mortality with no significant difference between groups $(\log \operatorname{rank}[p=0.16])$. The number of patients at risk over time is shown below each panel.

reason for suspension. A major bleeding event occurred in one patient from the control group; this event occurred in hospital care and eventually proved fatal.

The additional outpatient treatment prescribed to the study population was heterogeneous but evenly distributed between groups. Notably, the use of inhaled bronchodilators was lower in the sulodexide group $(p=0.01)$. A complete list

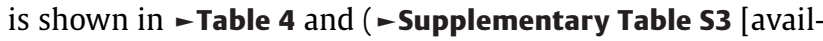
able in the online version]).

\section{Discussion}

This study evaluated sulodexide's therapeutic effect for patients in the early stages of COVID-19 in a real-life setting. Sulodexide was effective in decreasing the need for both hospital admission and supplemental oxygen treatment. Sulodexide-treated patients also had lower serum levels of CRP and D-dimer as markers for inflammatory and prothrombotic states.
This trial benefited from the use of the $\mathrm{C} 19 \mathrm{HC}$ calculator to identify patients at higher risk of progressing to a severe clinical stage, clustering each patient's age and various chronic comorbidities into a numeric risk value. ${ }^{26}$ In many of these patients, the endothelial surface layer may already be dysfunctional, ${ }^{32}$ and sulodexide can serve as a precursor for the synthesis of the GAGs needed for glycocalyx restoration. Animal studies show regrowth at 12 hours with recovery of the hemodynamically relevant glycocalyx in 5 to 7 days. ${ }^{10}$ The protective effect of sulodexide on vascular glycocalyx is also achieved through reducing the degradation of GAGs. ${ }^{33,34}$ The clinical progression of COVID-19 is associated with a severe inflammatory response in which symptoms can rapidly progress to full acute respiratory distress syndrome, which requires treatment with supplemental oxygen and/or hospital care. ${ }^{35,36}$ Sulodexide modulates and inhibits the generation of free radicals and critical inflammatory molecules, such as interleukin (IL)-1 $\beta(\beta)$, 
Table 3 Medication adherence and adverse events

\begin{tabular}{|c|c|c|c|c|}
\hline & Sulodexide $(n=124)$ & Placebo $(n=119)$ & RR $(95 \% \mathrm{Cl})$ & $p$-Value \\
\hline \multicolumn{5}{|l|}{ Medication adherence, $n$ (\%) } \\
\hline All the time ${ }^{a}$ & $91(73)$ & $99(83)$ & $1.13(0.99-1.29)$ & 0.06 \\
\hline Most of the time ${ }^{a}$ & $14(11)$ & $8(7)$ & $0.59(0.25-1.36)$ & 0.22 \\
\hline \multicolumn{5}{|l|}{ Medication suspended } \\
\hline Total & $19(15)$ & $12(10)$ & $1.81(0.88-3.74)$ & 0.10 \\
\hline Adverse event ${ }^{\mathrm{b}}$ & $8(6)$ & $6(5)$ & $0.78(0.27-2.18)$ & 0.63 \\
\hline Voluntary $^{c}$ & $11(8.8)$ & $6(5)$ & $0.56(0.21-1.48)$ & 0.24 \\
\hline \multicolumn{5}{|l|}{ Adverse event, $n(\%)$} \\
\hline Total $^{\mathrm{d}}$ & $96(77)$ & $85(71)$ & $1.08(0.93-1.25)$ & 0.28 \\
\hline $\begin{array}{l}\text { Abdominal discomfort } \\
\text { (gastritis, nausea, vomiting, or diarrhea) }\end{array}$ & $36(29)$ & $39(32)$ & $1.12(0.77-1.64)$ & 0.52 \\
\hline Headache & $96(77)$ & $85(71)$ & $0.92(0.79-1.07)$ & 0.28 \\
\hline Major bleeding & 0 & $1(0.8)$ & $3.12(0.12-75.96)$ & 0.48 \\
\hline Skin reaction & $3(2.4)$ & $5(4.2)$ & $1.73(0.42-7.10)$ & 0.44 \\
\hline
\end{tabular}

Abbreviations: $\mathrm{Cl}$, confidence interval; $n$, number patients; $\mathrm{RR}$, relative risk.

Note: Values are up to day 21 , the scheduled completion date of the trial. The main reason for the voluntary suspension of medication was an improvement in symptoms.

apatients while in the per-protocol outpatient setting.

bThree patients in the control group and five patients in the study group who suspended the medication due to an adverse event required hospital care due to severe clinical disease progression.

'No patient who suspended medication voluntarily needed hospital care or supplemental oxygen.

${ }^{\mathrm{d}}$ More than one adverse event could occur per patient.

IL-6, IL-8, and tumor necrosis factor- $\alpha{ }^{37,38}$ Although sulodexide's effect in modulating the glycocalyx can take time, its impact on modulating the endothelial response to these molecules (particularly IL6, which is very relevant in COVID-19) can occur in as little as 24 hours. ${ }^{34}$ This effect could help explain the reduced need for hospital care and supplemental oxygen observed in the sulodexide group.

Coagulopathy in severe COVID-19 is characterized by increased D-dimer. ${ }^{39}$ Although nonspecific, this increase suggests thrombus generation and fibrinolysis possibly attributable to a coagulation cascade activation secondary to systemic inflammatory response syndrome. ${ }^{40}$ However, limited data exist regarding their value in the outpatient setting. In the hospital setting, levels of biomarkers such as D-dimer and CRP have been proven to be helpful in identifying clinical severity of the disease, ${ }^{41}$ including occurrence of mortality. ${ }^{42}$ Lower D-dimer levels are therefore suggestive of a decreased severity of the disease, ${ }^{43}$ a relationship that has prompted the use of anticoagulation, though the debate on proper dosing and duration is ongoing. ${ }^{44,45}$ Sulodexide has been proposed as an option for targeting thromboembolic risk in COVID-19 patients. ${ }^{46}$ The drug's antithrombotic effect is a result of its interaction with antithrombin and heparin cofactor II. ${ }^{47}$ Thus, the lower D-dimer and CRP levels observed with sulodexide treatment could result from the drug's effect against the thromboinflammation response and microvascular thrombus formation. Although the number of confirmed thromboembolic events was low in (and similar among) both groups in our study population, we strongly suspected (but could not confirm) additional clinical cases.
In addition, reports on a select group of patients under prolonged anticoagulation who later tested positive for COVID-19 presented better outcomes ${ }^{48}$ and D-dimer elevation was common upon hospital admission. ${ }^{49}$ We found that almost $15 \%$ of the study patients had elevated Ddimer levels at baseline. We also observed that once patients required hospital care, there was no betweengroup difference in the total number of days of hospital care or the need for mechanical ventilation or hemodialysis, and there was also no between-group difference in mortality. These findings suggest that the severe systemic disease complications may obscure sulodexide's effect once patients become critically ill, highlighting the importance of early action.

Moreover, other anticoagulants are known to have secondary, nonanticoagulant properties that can be beneficial to COVID-19 patients, particularly unfractionated heparin and $\mathrm{LMWH}^{21,46}$; however, the risk of bleeding that accompanies these treatments has limited their use in the hospital setting. Sulodexide, in contrast, can be used early in treatment with no significant risk of side effects and no need to monitor blood for dose control.

Several limitations of this study must be acknowledged. Asymptomatic carriers and a lack of widespread diagnostic testing have made it difficult to establish the disease's true incidence. Consequently, the posthoc sample size was relatively small, mortality was underpowered, and the $p$-value for hospitalization was not especially strong. Nonmajor, clinically relevant bleeding was not assessed. At the time of the study, it took an average of 5 days to receive the SARS- 
Table 4 Concomitant medication

\begin{tabular}{|c|c|c|c|c|}
\hline & Sulodexide group $(n=124)$ & Placebo group $(n=119)$ & RR $(95 \% \mathrm{Cl})$ & $p$-Value \\
\hline \multicolumn{5}{|l|}{ Medication before trial, $n(\%)$} \\
\hline Aspirin & $33(27)$ & $44(37)$ & $0.71(0.49-1.04)$ & 0.08 \\
\hline Oral hypoglycemic drugs & $19(15)$ & $27(23)$ & $0.67(0.39-1.14)$ & 0.14 \\
\hline Insulin & $14(11)$ & $18(15)$ & $0.74(0.38-1.43)$ & 0.37 \\
\hline ACE inhibitors & $22(18)$ & $32(27)$ & $0.65(0.40-1.06)$ & 0.09 \\
\hline Other antihypertensive drugs & $45(36)$ & $41(34)$ & $1.05(0.74-1.48)$ & 0.76 \\
\hline Statins & $14(11)$ & $16(13)$ & $0.83(0.42-1.64)$ & 0.61 \\
\hline \multicolumn{5}{|c|}{ Medication added during the trial, $n(\%)$} \\
\hline Paracetamol & $78(63)$ & $82(69)$ & $0.91(0.76-1.09)$ & 0.32 \\
\hline LMWHs & $12(10)$ & $16(13)$ & $0.71(0.35-1.45)$ & 0.36 \\
\hline NOACS & $9(7)$ & $11(9)$ & $0.78(0.33-1.82)$ & 0.57 \\
\hline Ivermectin & $54(44)$ & $59(50)$ & $0.87(0.67-1.15)$ & 0.34 \\
\hline Hydroxychloroquine & $46(37)$ & $36(30)$ & $1.22(0.85-1.75)$ & 0.26 \\
\hline Corticosteroids & $79(64)$ & $73(61)$ & $1.17(0.97-1.40)$ & 0.08 \\
\hline Statins & $25(20)$ & $21(18)$ & $1.14(0.67-1.92)$ & 0.61 \\
\hline Vitamins-supplements & $95(77)$ & $101(85)$ & $0.90(0.79-1.02)$ & 0.10 \\
\hline Antibiotics & $41(33)$ & $35(29)$ & $1.12(0.77-1.63)$ & 0.54 \\
\hline Other NSAIDs & $67(54)$ & $56(47)$ & $1.14(0.89-1.47)$ & 0.27 \\
\hline Omeprazole & $98(79)$ & $105(88)$ & $0.88(0.78-0.98)$ & 0.03 \\
\hline Antacids & $44(35)$ & $36(30)$ & $1.17(0.81-1.68)$ & 0.38 \\
\hline Inhaled bronchodilators & $70(56)$ & $85(71)$ & $0.79(0.65-0.95)$ & 0.01 \\
\hline Oseltamivir & $33(27)$ & $28(24)$ & $1.13(0.73-1.74)$ & 0.58 \\
\hline
\end{tabular}

Abbreviations: ACE, angiotensin-converting enzyme; Cl, confidence interval; LMWHs, low-molecular-weight heparins; $n$, number of patients; NOACs, non-vitamin K antagonist oral anticoagulants (novel oral anticoagulants); NSAIDs, nonsteroidal anti-inflammatory drugs; RR, relative risk.

Note: The showed list only includes medications used in the outpatient setting. Patients usually received more than one additional medication.

CoV-2 RT-PCR test results. Consequently, given the timesensitive nature of sulodexide's expected benefit, patients were included under clinical suspicion alone. We did not foresee some of the logistical limitations that stemmed from the region's pandemic lockdown, resulting in poor access to Doppler ultrasound and computed tomography scans. The lead researcher was not blinded to group allocation. During the outpatient setting, the numbers and types of medications prescribed to the study population were heterogenic. Although these factors were evenly distributed between the groups, one must still consider them when interpreting the results.

In summary, when used in the early stages of COVID19 , the synergistic activity of sulodexide's pleiotropic effects on different biological targets may play an essential role in limiting disease progression, thus resulting in a reduced need for supplemental oxygen and hospital care-as was observed in this trial. These results have promising implications that indicate a contribution toward patients' well-being, making sulodexide a valuable medication in the outpatient treatment of COVID-19. These findings justify further confirmatory multicenter studies.

\section{What is known about this topic?}

- The use of low-molecular-weight heparin (LMWH) has reduced mortality in critically ill COVID-19 patients.

- There are insufficient data regarding the benefit of anticoagulation in SARS-COV-2-positive persons with mild to moderate COVID-19.

- Patients' laboratory values during the different clinical stages of COVID-19 are rarely available outside the hospital setting.

\section{What does this paper add?}

- Treatment of mildly to moderately diseased COVID-19 patients may be improved by sulodexide's antithrombotic effect without increasing the risk of bleeding.

- The increase in D-dimer and C-reactive protein levels is lower with sulodexide compared with placebo during the outpatient treatment of COVID-19.

- Oral treatment with sulodexide may be an alternative to other oral anticoagulants due to its multiple nonantithrombotic pharmacological actions. 


\section{Note}

The data analyzed and presented in this study are available from the corresponding author upon reasonable request, providing that the request meets local ethical and research governance criteria. This trial is listed in the ISRCTN registry with the study ID ISRCTN59048638.

\section{Funding}

This study was independently initiated by the lead researcher and partially funded by Alfasigma Mexico, with the latter providing the sulodexide and placebo capsules for the duration of the trial. Alfasigma did not take part in enrolling trial participants; collecting, managing, analyzing, and interpreting the data; or the decision to submit the report for publication.

\section{Conflict of Interest}

A.G.O. has received speaker fees, honoraria, and travel reimbursement from Alfasigma Mexico for research unrelated to this study. The other authors have no competing interests to declare.

\section{Acknowledgments}

We thank Dr. Sarah Onida (Imperial College London) and Dr. Nick Morrison (Center for Vein Restoration Phoenix) for their insight during the developing phase of the trial, and also Dr. Jawed Fareed (Loyola University Chicago) and the anonymous reviewers who helped with their comments to improve the early version of this article.

\section{References}

1 World Health Organization. COVID-19 early epidemiologic and clinical investigations for public health. Accessed April 15, 2020 at: https://www.who.int/docs/default-source/coronaviruse/200218-early-investigations-one-pager-v1-eng.pdf? sfvrsn=8aa0856_14

2 Dawood FS, Ricks P, Njie GJ, et al. Observations of the global epidemiology of COVID-19 from the prepandemic period using web-based surveillance: a cross-sectional analysis. Lancet Infect Dis 2020;20(11):1255-1262

3 COVID-19 Mexico. Datos generales: casos confirmados. Secretaria de Salud. Gobierno de Mexico. Accessed June 7, 2020 at: https:// coronavirus.gob.mx/datos/

4 Schutte AE, Harrison DG. Immunity, inflammation and the vasculature in the COVID-19 era. J Hypertens 2020;38(09): 1701-1702

5 Gencer S, Lacy M, Atzler D, van der Vorst EPC, Döring Y, Weber C. Immunoinflammatory, thrombohaemostatic, and cardiovascular mechanisms in COVID-19. Thromb Haemost 2020;120(12): 1629-1641

6 Campbel C, Kahwash K. Microvascular thrombi in COVID-19. American College Cardiology, 25 January 2021 [Online]. Accessed January 29, 2021 at: https://www.acc.org/latest-in-cardiology/ articles/2021/01/25/14/28/microvascular-thrombi-in-covid-19

7 Carsana L, Sonzogni A, Nasr A, et al. Pulmonary post-mortem findings in a series of COVID-19 cases from northern Italy: a twocentre descriptive study. Lancet Infect Dis 2020;20(10): $1135-1140$

8 Moore JB, June $\mathrm{CH}$. Cytokine release syndrome in severe COVID19. Science $2020 ; 368(6490): 473-474$
9 Ackermann M, Verleden SE, Kuehnel M, et al. Pulmonary vascular endothelialitis, thrombosis, and angiogenesis in Covid-19. N Engl J Med 2020;383(02):120-128

10 Becker BF, Jacob M, Leipert S, Salmon AH, Chappell D. Degradation of the endothelial glycocalyx in clinical settings: searching for the sheddases. Br J Clin Pharmacol 2015;80(03):389-402

11 McGurnaghan SJ, Weir A, Bishop J, et al; Public Health Scotland COVID-19 Health Protection Study Group Scottish Diabetes Research Network Epidemiology Group. Risks of and risk factors for COVID-19 disease in people with diabetes: a cohort study of the total population of Scotland. Lancet Diabetes Endocrinol 2021;9 (02):82-93

12 Evans PC, Rainger GE, Mason JC, et al. Endothelial dysfunction in COVID-19: a position paper of the ESC Working Group for Atherosclerosis and Vascular Biology, and the ESC Council of Basic Cardiovascular Science. Cardiovasc Res 2020;116(14): 2177-2184

13 Masola V, Zaza G, Onisto M, Lupo A, Gambaro G. Glycosaminoglycans, proteoglycans and sulodexide and the endothelium: biological roles and pharmacological effects. Int Angiol 2014;33 (03):243-254

14 Li T, Liu X, Zhao Z, Ni L, Liu C. Sulodexide recovers endothelial function through reconstructing glycocalyx in the balloon-injury rat carotid artery model. Oncotarget 2017;8(53):91350-91361

15 Coccheri S, Mannello F. Development and use of sulodexide in vascular diseases: implications for treatment. Drug Des Devel Ther 2013;8:49-65

16 Zielinski A, Zabel M, Wysocka T, Urbanek T, Suminska K. Sulodexide activates glycocalyx restorations in patients with chronic venous disease. Vasc Insight Nautilus 2019;1:17-18

17 Mannello F, Ligi D, Canale M, Raffetto JD. Sulodexide downregulates the release of cytokines, chemokines, and leukocyte colony stimulating factors from human macrophages: role of glycosaminoglycans in inflammatory pathways of chronic venous disease. Curr Vasc Pharmacol 2014;12(01):173-185

18 Matta PManello F, Ferrari P, Augus G. Vascular pathologies and inflammation: The anti-inflammatory properties of sulodexide. Ital J Vasc Endovasc Surg 2012;2(03):1-7

19 Pompilio G, Integlia D, Raffetto J, Palareti G. Comparative efficacy and safety of sulodexide and other extended anticoagulation treatments for prevention of recurrent venous thromboembolism: a Bayesian network meta-analysis. TH Open 2020;4(02): e80-e93

20 Billett HH, Reyes-Gil M, Szymanski J, et al. Anticoagulation in COVID-19: effect of enoxaparin, heparin, and apixaban on mortality. Thromb Haemost 2020;120(12):1691-1699

21 Drouet L, Harenberg J, Torri G. The multiple faces of heparin: opportunities in COVID-19 infection and beyond. Thromb Haemost 2020;120(10):1347-1350

22 Harenberg J, Bauersachs R, Ageno W. Does chronic treatment with oral anticoagulants ameliorate the clinical course of severe acute respiratory syndrome Coronavirus 2 (SARS-CoV-2) infection in Coronavirus disease 2019 (COVID-19)? Semin Thromb Hemost 2020. Doi: $10.1055 /$ s-0040-1715091

23 Duvignaud A, Lhomme E, Pistone T, et al; COVERAGE study group. Home treatment of older people with symptomatic SARS-CoV-2 infection (COVID-19): a structured summary of a study protocol for a multi-arm multi-stage (MAMS) randomized trial to evaluate the efficacy and tolerability of several experimental treatments to reduce the risk of hospitalisation or death in outpatients aged 65 years or older (COVERAGE trial). Trials 2020;21(01):846

24 Cao R-N, Tang L, Xia Z-Y, Xia R. Endothelial glycocalyx as a potential theriapeutic target in organ injuries. Chin Med J (Engl) 2019;132(08):963-975

25 Kaur S, Tripathi DM, Yadav A. The enigma of endothelium in COVID-19. Front Physiol 2020;11:989 
26 IMSS. Calculadora de complicacion de salud por COVID-19. Gobierno de Mexico: IMSS. Accessed June 6, 2020 at: http:// www.imss.gob.mx/covid-19/calculadora-complicaciones/htm

27 González Ochoa A. Sulodexide and phlebotonics in the treatment of venous ulcer. Int Angiol 2017;36(01):82-87

28 Andreozzi GM, Bignamini AA, Davì G, et al; SURVET Study Investigators. Sulodexide for the prevention of recurrent venous thromboembolism: the sulodexide in secondary prevention of recurrent deep vein thrombosis (SURVET) study: a multicenter, randomized, double-blind, placebo-controlled trial. Circulation 2015;132(20):1891-1897

29 Lineamientos para la atencion de pacientes con COVID-19. Gobierno de Mexico: Gob.mx. Accessed February 15, 2021. Accessed 2021 at: http://cvoed.imss.gob.mx/wp-content/uploads/2020/02/Linemaineto-cl\%C3\%ADnico-COVID-19-CCINSHAE-14feb2020.pdf.pdf.pdf. pdf

30 Algoritmos interinos para la atencion del COVID-19. Instituto Mexicano Seguro Social. Accessed 2020 at: http://educacionensalud.imss.gob.mx/es/system/files/Algoritmos_interinos_COVID19_CTEC.pdf

31 Gonzalez Ochoa AJ, Carrillo J, Manríquez D, Manrique F, Vazquez AN. Reducing hyperpigmentation after sclerotherapy: a randomized clinical trial. J Vasc Surg Venous Lymphat Disord 2021;9(01):154-162

32 Froldi G, Dorigo P. Endothelial dysfunction in coronavirus disease 2019 (COVID-19): gender and age influences. Med Hypotheses 2020;144(110015):110015

33 Jarzabek K, Gabryel B, Urbanek T. Sulodexide in the treatment of vascular disease: its therapeutic action on the endothelium. Phlebol Rev. 2016;4:51-59

34 Ciszewicz M, Polubinska A, Antoniewicz A, Suminska-Jasinska K, Breborowicz A. Sulodexide suppresses inflammation in human endothelial cells and prevents glucose cytotoxicity. Transl Res 2009;153(03):118-123

35 Wise J. Covid-19: study reveals six clusters of symptoms that could be used as a clinical prediction tool. BMJ 2020;370:m2911

36 Chen J, Qi T, Liu L, et al. Clinical progression of patients with COVID-19 in Shanghai, China. J Infect 2020;80(05):e1-e6

37 Mannello F, Medda V, Ligi D, Raffetto JD. Glycosaminoglycan sulodexide inhibition of MMP-9 gelatinase secretion and activity: possible pharmacological role against collagen degradation in vascular chronic diseases. Curr Vasc Pharmacol 2013;11(03):354-365

38 Urbanek T, Zbigniew K, Begier-Krasińska B, Baum E, Bręborowicz A. Sulodexide suppresses inflammation in patients with chronic venous insufficiency. Int Angiol 2015;34(06):589-596

39 Marchandot B, Trimaille A, Curtiaud A, et al. Staging severity of COVID-19 according to hemostatic abnormalities (CAHA score). Thromb Haemost 2020;120(12):1716-1719
40 Wu C, Chen X, Cai Y, et al. Risk factors associated with acute respiratory distress syndrome and death in patients with Coronavirus disease 2019 pneumonia in Wuhan, China. JAMA Intern Med 2020;180(07):934-943

41 Valerio L, Ferrazzi P, Sacco C, et al; Humanitas COVID-19 Task Force. Course of D-dimer and C-reactive protein levels in survivors and nonsurvivors with COVID-19 pneumonia: a retrospective analysis of 577 patients. Thromb Haemost 2021;121(01): 98-101

42 Yao Y, Cao J, Wang Q et al. D-dimer as a biomarker for disease severity and mortality in COVID-19 patients: a case control study. J Intensive Care 2020;8(01):49

43 Ranucci M, Ballotta A, Di Dedda U, et al. The procoagulant pattern of patients with COVID-19 acute respiratory distress syndrome. J Thromb Haemost 2020;18(07):1747-1751

44 Spyropoulos AC, Levy JH, Ageno W, et al; Subcommittee on Perioperative, Critical Care Thrombosis, Haemostasis of the Scientific, Standardization Committee of the International Society on Thrombosis and Haemostasis. Scientific and Standardization Committee communication: clinical guidance on the diagnosis, prevention, and treatment of venous thromboembolism in hospitalized patients with COVID-19. J Thromb Haemost 2020;18 (08):1859-1865

45 Gerotziafas GT, Catalano M, Colgan M-P, et al; Scientific Reviewer Committee. Guidance for the management of patients with vascular disease or cardiovascular risk factors and COVID-19: position paper from VAS-European Independent Foundation in Angiology/Vascular Medicine. Thromb Haemost 2020;120(12): $1597-1628$

46 Bikdeli B, Madhavan MV, Gupta A, et al; Global COVID-19 Thrombosis Collaborative Group. Pharmacological agents targeting thromboinflammation in COVID-19: review and implications for future research. Thromb Haemost 2020;120(07): 1004-1024

47 Połubińska A, Staniszewski R, Baum E, Sumińska-Jasińska K, Bręborowicz A. Sulodexide modifies intravascular homeostasis what affects function of the endothelium. Adv Med Sci 2013;58 (02):304-310

48 Fröhlich GM, Jeschke E, Eichler U, et al. Impact of oral anticoagulation on clinical outcomes of COVID-19: a nationwide cohort study of hospitalized patients in Germany. Clin Res Cardiol 2021. Doi: $10.1007 /$ s00392-020-01783-x

49 Malik SUF, Chowdhury PA, Hakim A, Islam MS, Alam MJ, Azad AK. Blood biochemical parameters for assessment of COVID-19 in diabetic and non-diabetic subjects: a cross-sectional study. Int J Environ Health Res 2021. Doi: 10.1080/09603123.2021. 1879741 